\title{
Etica academică în contextul pandemiei Covid 19: metode eficiente utilizate la nivel instituţional ${ }^{1}$
}

\section{Tünde GIURGIUMAN ${ }^{1 *}$, Marius DEACONU², Sorin Daniel VÂTCĂ ${ }^{1}$}

1 Universitatea de Științe Agricole și Medicină Veterinară Cluj-Napoca; tunde.giurgiuman@usamvcluj.ro; sorin.vatca@usamvcluj.ro

2 Consiliul de etică și management universitar; marius.deaconu@uefiscdi.ro

* Corespondență: tunde.giurgiuman@usamvcluj.ro

Rezumat: In contextul situației pandemice provocate de Covid 19, etica și valorile academice au avut de suferit în ceea ce privește informarea, promovarea și diseminarea normelor de conduită academică și profesională. Toate instituţiile publice au la bază fie codul de etică și deontologie, fie regulamente de conduită profesională pentru a contracara problemele unui comportament inadecvat. Prin urmare, au fost necesare noi metode de promovare adaptate comunicării online. Noile metode utilizate au facilitat transmiterea informaţiilor, care vizează drepturile și obligațiile studenților, normele de comportament și conduită ale personalului academic şi auxiliar, facilitând astfel respectarea standardelor de etică și conduită acceptate și impuse de mediul universitar. Lucrarea de faţă abordează problematica metodelor utilizate în această perioadă, în care mediul on-line a constituit sfera de desfăşurare a tuturor acţiunilor întreprinse. E-mail-urile de informare și promovare, întâlnirile individuale sau în grup, dezbaterile pe diverse teme, ședințele de consiliere şi-au găsit un teren propice de manifestare în mediul virtual. Așadar, unei universităţi, care în societatea actuală are rolul de a reprezenta un pol de excelenţă cu funcţie de formator de opinie şi atitudine la toate nivelurile ei, îi revine dificila sarcină de a promova și veghea asupra valorilor morale şi etice.

Cuvinte cheie: etică și integritate, valori academice, consiliere etică, promovarea eticii, metode, Covid-19
Citation: Giurgiuman, T., Deaconu, M. \& Vâtcă, S.D. (2021). Etica academică în contextul pandemiei Covid 19: metode eficiente utilizate la nivel instituțional. Revista Etică și Deontologie. 1(1), 25-31

https://doi.org/10.52744/RED.2021.01.04

Publisher's Note: RED stays neutral with regard to jurisdictional claims in published maps and institutional affiliations.

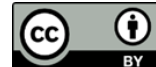

Copyright: (C) 2021 by the authors. Submitted for possible open access publication under the terms and conditions of the Creative Commons Attribution (CC BY) license (https://creativecommons.org/ licenses/by/4.0/).

${ }^{1}$ Articol prezentat în cadrul Conferinței Internaționale Valorile Etice în Societatea Actuală - VESA 2021 (3-5 iunie). 


\section{Introducere}

În orice societate funcțională, liniile directoare sunt reprezentate de normele și valorile general acceptate și promovate, aceste norme și valori fiind construite pe baza unei ideologii culturale forjate și promovate prin definiție de mediul universitar.

Universitatea ca instituție emblematică are rolul de a reprezenta un pol de excelență, o instanță aulică cu funcție de formator de atitudine și opinie la toate nivelurile societății, începând cu cei care activează în structura instituției, cadre didactice, studenți, personal auxiliar etc. cât și continuând cu cei din afara ei.

Etica universitară este intrinsec legată de o dimensiune axiologică, adică de anumite valori (Rothman, 2017). Fundamentele axiologice ale eticii universitare trimit către implicarea acțiunii conștiinței umane în construirea de atitudini rezultate din demersul de cunoaștere de tip rațional, demers gnoseologic care reflectă o structură obiectivă a realității prin intermediul căreia subiectul cunoscător instituie o structură semnificantă.

În acest context constituirea criteriilor valorice reprezintă un demers intelectual construit de către subiectul cunoscător. Aici subiectul privilegiază atitudini, acțiuni și creații care prin calitățile lor ajută la îndeplinirea unor obiective sau aspirații de utilitate generală. Internalizarea unui set de valori în conștiința colectivă ar trebui să conducă acțiunea socială spre o direcție principială în care principiile vor prevala asupra preferințelor individuale sau utilitariste. Sistemele valorice sunt specifice fiecărei culturi, ele fiind însă supuse unor modificări pe parcursul istoriei și a evoluției societății (Androniceanu, 1990; Androniceanu, 1998).

\section{Valorile etice - aspecte fundamentale}

Există norme și valori general umane care vin în întâmpinarea unor aspirații și trebuințe universale, oamenii apreciindu-le pe parcursul tuturor etapelor evoluției societății și în toate perioadele istorice. În construcția propriei viziuni a individului despre lume, rolul fundamental îl deține educația, de care individul are parte în decursul primelor etape ale existenței sale dar și mai târziu din diverse direcții, în special grație mediului social în care trăiește și activează (Mihăilescu, 2019). Fundamentul universului axiologic al fiecărui individ îl reprezintă valorile transgeneraționale pe care acesta le dobândește în decursul educaţiei lui primare primite în interiorul familiei. Universitatea obține cele mai bune rezultate în rolul ei de formator de opinie atunci când un număr cât mai mare dintre subiecți au dobândit deja în cursul educației primare din sânul familiei o viziune solidă asupra valorilor și normelor general acceptate.

Valorile eticii academice reprezintă o structură în care sunt formalizate regulile morale și de integritate ale acestui domeniu (Ștefan, 2018; Socaciu et. al., 2018), ca expresie a poziției acceptate în raport cu ceea ce este dezirabil sau nu în relațiile din cadrul mediului academic. Normele și valorile au un rol de ghid orientând ceea ce se 
întâmplă în învățământul superior la nivelul activității formative și de transmitere a informațiilor dinspre cadrele didactice către studenți, precum și interacțiunea care are loc în interiorul mediului universitar, aici fiind vorba despre relațiile și raporturile între cei care fac parte din comunitatea academică și între ei și colaboratorii din afara universității.

Sistemul de valori etice agreate în universitate se referă la mai multe aspecte fundamentale (Boehm et. al., 2009) prima dintre acestea fiind libertatea academică, care are ca și obiectiv poziționarea universității ca o zonă liberă de influențe și condiționări exterioare care nu sunt de natură legală sau științifică.

Un al doilea aspect fundamental se referă la gradul ridicat de autonomie personală a cadrelor didactice văzută ca și condiție necesară pentru îndeplinirea deplină a obiectivelor educaționale propuse în niște parametri optimi de eficiență.

0 a treia problemă fundamentală discutată de noi aici se referă la natura relațiilor între membrii corpului profesoral universitar impunându-se eludarea situațiilor cu potențial de a conduce la conflicte de interes și probleme de incompatibilitate, care ar putea afecta sau impieta asupra activităților educative specifice ale universității precum și a favoriza unele acțiuni interesate sau părtinitoare care să ducă la avantaje nemeritate pentru unii membrii din acest mediul profesional academic.

Un alt aspect asupra căruia am dori să insistăm este profesionalismul, care implică pe lângă criteriul competenței în activitatea didactică și obligația de natură etică de a sprijini interesul formativ fundamental al studenților, corectitudinea în evaluarea și promovarea performanțelor obținute de aceștia evitând în același timp tratamentul preferențial nejustificat al acestora.

Penultimul aspect relevant se referă la responsabilitatea care incumbă statutului de cadru didactic universitar în domeniul implicării în viața profesională și publică, în calitatea pe care cadrul didactic o are ca model etic de vârf și formator de opinie necontestat atât în mediul studențesc, cât și în viața publică.

Ultimul aspect de neeludat aici se referă la promovarea principiului meritocrației care vizează cultivarea, recunoașterea și valorizarea performanței universitare și a realizărilor didactice precum și aprecierea loaialității în raport cu instituția și colegii corpului profesoral.

\section{Aspecte ale comunicării generate de pandemia de Covid-19}

În situații de criză, așa cum este pandemia Covid 19, care a limitat modalitățile obișnuite de comunicare intra-instituțională dar și pe cele cu mediul exterior, a fost imperios necesară găsirea unor alternative comunicaționale viabile și eficiente la cele clasice, ceea ce a impus modificări ale managementului în acest sens (Băloiu, 1995). Pandemia generată de virusul Covid-19 ne-a impus să trăim diferit, aşa cum nu am mai făcut-o şi aceasta a cauzat efecte nu doar în viața noastră privată dar și în cea profesională. Aceste circumstanțe ne-au schimbat modul de a trăi și ne-au forțat să descoperim noi modalități de interacțiune, comunicare și exercitare a activităților.

Întreaga comunitate academică (angajați și studenți) a fost pusă în situația de a face față schimbărilor profunde ale metodelor de relaționare, comunicare, de lucru și ale tensiunilor emoționale care s-au accentuat din cauza incertitudinii. 
Nesiguranța indusă de această criză, a afectat capacitatea noastră de a procesa informații, care a tins să fie una mai limitată decât înainte deoarece, cu cât informațiile sunt mai abstracte sau mai complicate, cu atât este mai dificil pentru noi să atribuim sensul real informațiilor primite.

Modul nostru de a percepe lucrurile face de asemenea diferența. Când emoționalul (panica) ia locul rațiunii, este greu să privim lucrurile altfel doar printro conştientizare rațională a situației de fapt. În aceste momente putem accepta realitatea așa cum este și credem că lumea va reveni la normal și ne va putea oferi oportunități pe care înainte nu le-am accesat.

În contextul pandemiei, așa cum era de așteptat, inclusiv promovarea eticii şi a valorilor academice, facilitarea transmiterii informațiilor privind respectarea normelor, a valorilor și a procedurilor cuprinse în Codurile de Etică universitară au suferit modificări.

Instituțiile, având la bază coduri de conduită pentru a aborda problematica comportamentului neetic s-au văzut nevoite să-şi adapteze metodele de promovare utilizate anterior la noua situație. Metodele utilizate au facilitat transmiterea informațiilor vizând drepturile şi obligațiile studenților, normele de comportament ale personalului academic şi non-academic facilitând respectarea standardelor etice şi morale acceptate în mediul universitar.

Lucrarea de față și-a propus să abordează metodologia utilizată cu succes în această perioadă în ceea ce privește promovarea valorilor etice academice şi supravegherea respectării conținuturilor codurilor de etică şi deontologie profesională acceptate la nivel național. Desigur, ne referim cu precădere la mediul on-line, care a constituit sfera de desfăşurare a tuturor acțiunilor întreprinse.

Rețelele de internet, platformele de intra-net, bazele de date preexistente (existența comunității on-line constituită din angajați, studenți, foști absolvenți, parteneri şi colaboratori externi) au reprezentat instrumentele de bază pentru:

$\square$ diseminarea informaţiilor;

$\square$ facilitarea accesului la conținuturi;

clarificarea unor aspecte mai puțin transparente;

$\square$ identificarea și găsirea unor soluții practice pentru rezolvarea problemelor;

$\square$ transmiterea diverselor tipuri de documente.

Cele mai uzuale metode s-au dovedit a fi:

$>$ mail-urile de promovare trimise angajaților, studenților, personalului auxiliar, a tuturor celor implicați în activitatea instituțională;

$>$ întâlnirile individuale sau de grup în mediul on-line;

$>$ şedințele de lucru on-line;

$>$ şedințele de consiliere etică on-line;

$>$ dezbaterile pe diverse teme în mediul on-line etc.

Mail-urile de promovare: $\mathrm{Nu}$ au reprezentat o noutate absolută și desigur, doar că înainte de pandemie numărul acestora a fost mult mai redus. Dacă înainte, oamenii în general au preferat situațiile de comunicarea față în față, de această dată s-au văzut nevoiți să apeleze doar la mail-uri. Astfel s-a facilitat accesul angajaților, 
studenților, personalului auxiliar, a tuturor celor aflați în contact cu mediul academic extrem de rapid la conținutul Codului de Etică. Pe baza informațiilor, aceştia şi-au putut formula propriile păreri, opinii, dileme legate de anumite aspecte şi au putut utiliza acest instrument în scopul lămuririi aspectelor neclare.

Reprezentanții, membrii Comisiei de etică s-au asigurat ca în cel mai scurt timp să ofere răspunsuri cât mai complexe la situațiile formulate.

Mail-urile, în general pot reprezenta o modalitate eficientă și dinamică de promovare a transmiterii informațiilor și, subiacent, promovează normele și valorile deontologice legate de acuratețea și exactitatea comunicării într-o manieră poate superioară transmiterii informației în varianta față în față sau directă. Cei care au conceput și transmis aceste mail-uri (în principal cadre didactice) au încercat să răspundă cât mai eficient nevoilor celor implicați. Ei au avut posibilitatea de a selecta cele mai potrivite conținuturi, de a oferi un climat emoțional adecvat, un suport moral construit pe percepția unei activități funcționale la nivel intra-instituțional, să stabilească scopuri în funcție de necesitățile survenite și să monitorizeze acțiunile întreprinse.

Nu au fost însă lipsite nici situațiile în care receptorii acestor mesaje au resimțit anumite emoții negative ca urmare a neînțelegerii conținuturilor unor materiale primite, s-au putut simți însingurați, urmare a absenței interacțiunii directe $\mathrm{cu}$ membrii comisiilor sau au încercat un sentiment de frustrare generat de provocările ce vizează limitarea comunicării online și funcționarea platformelor utilizate.

Întâlnirile individuale sau de grup în mediul on-line: Întâlnirile individuale sau cele de grup desfăşurate exclusiv în mediul on-line au constituit o noutate absolută. Dacă aceste instrumente, întâlnirile individuale și de grup, înainte au fost utilizate pe un teren real, de această dată au fost transpuse în mediul virtual.

În cazul persoanelor introvertite, această metodă s-a dovedit a fi mult mai eficientă şi anume, faptul de a nu intra într-un birou, de a nu avea o comunicare completă sub toate formele ei (verbal, non-verbal și paraverbal), de a nu interacționa direct cu interlocutorii, i-au ajutat pe unii să apeleze mult mai uşor și mai des la suportul oferit de membrii comisiei de etică.

Ședințele de lucru on-line: Ședințele de lucru în mediul on-line au înlesnit o comunicare mai directă, mult mai rapidă, realizate direct din mediul confortului personal, de multe ori nemaifiind vorba de emoțiile confruntării acelei persoane față în față.

Avantajele economice, de confort, de siguranță, confidențialitate, flexibilitate au reprezentat atuurile acestor ședințe, care au permis alocarea doar a timpului necesar susținerii efective a ședințelor, fără a mai lua în calcul și timpul necesar deplasării fizice, au asigurat confortul necesar din propria casă, au scăzut stresul cauzat de purtarea măștii, anxietatea cauzată de întâlnirile față în față, și programul imprevizibil, etc.

Conversațiile au devenit în majoritatea situațiilor mai eficiente și s-a câștigat timp, acesta nemaifiind irosit cu small talk-uri ce nu aduceau oricum valoare conversației. Acest sistem a adăugat o notă benefică de informal comunicării. 


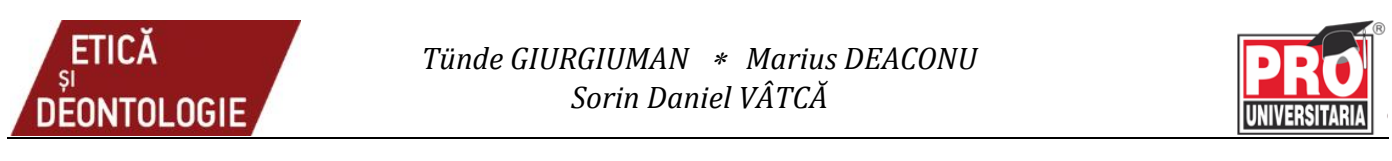

Ședințele de consiliere etică on-line: Ședințele individuale de consiliere etică au asigurat o libertate mai mare în abordarea subiectelor delicate, unde ascultarea activă, răbdarea, alegerea cu grijă a cuvintelor și să nu uităm zâmbetul, au facilitat deschiderea interlocutorilor, făcând astfel posibilă lămurirea unor aspecte controversate, dar și găsirea soluțiilor și a răspunsurilor dorite. În funcție de confortul psihic al interlocutorului, comunicarea se putea realiza inclusiv cu camera oprită. Această manieră a adus un plus în direcția personalizării inter-subiectivității realizate între consilier și consiliat, adică legătura empatică și gradul de deschidere și sinceritate realizat este mai ridicat.

Dezbaterile în on-line: Dezbaterile pe diverse teme au suferit cu siguranță cel mai mult. Metodele activ-participative utilizate anterior pandemiei, care aveau rolul de a oferi percepții diferite asupra unui subiect, moduri de abordare multiple, soluționări diverse, acum au fost limitate de realizarea în mod indirect al comunicării în mediul on-line, virtual.

\section{Concluzii}

Actuala pandemie de Covid 19 a reprezentat o piatră de încercare pentru conștientizarea nivelului solidarității sociale precum și a rezilienței individuale a membrilor societății în fața unei situații neprevăzute de risc sanitar și social major care a impus volens-nolens constrângeri comportamentale și de consum fără precedent în ultimele decenii în societățile democratice în a face față situației complexe generate de această epidemie și de consecințele ei, atât la nivel pragmatic, cât și la nivel emoțional.

Reperele axiologice internalizate ale fiecărui individ au reprezentat un puternic atu în depășirea impactului pe care această pandemie l-a avut asupra fiecăruia dintre noi.

Prin utilizarea tehnologiei numărul interacțiunilor a crescut, însă în detrimentul profunzimii lor. Într-o societate normală, instituția școlară, fie că ne referim la cea primară, gimnazială sau universitară are rolul de a crea o identitate de generație, de a dezvolta lidership-ul, capacitatea de a-i influența pe ceilalți (Duca, 2007; Mihăilescu, 2019) iar acest lucru nu se poate realiza doar într-un mediu virtual.

Metodele comunicaționale alternative modalităților obișnuite de comunicare intra-instituțională dar și cu mediul exterior, scurt prezentate și discutate în prezentul articol, prezintă, cel puțin din perspectiva asigurării unui climat de etică și integritate atât aspecte pozitive cât și aspecte negative.

Aspectele pozitive observate în utilizarea alternativelor comunicaționale privind promovarea eticii în pandemie sunt:

$\square$ libertate mai mare în abordarea subiectelor delicate;

conversații mai eficiente și timp câștigat;

$\square$ ascultare activă;

$\square$ răbdarea manifestată de interlocutori;

$\square$ alegerea cu grijă a cuvintelor;

] comunicare mai directă, fără aspecte emoționale prea ample. 
Aspectele negative observate în utilizarea alternativelor comunicaţionale privind promovarea eticii în pandemie constau în faptul că:

口 informațiile, mesajele pot fi transmise/interpretate defectuos, neavând întreaga paletă de stimuli vizuali ce complementează comunicarea, nu pot fi citite vizual intențiile interlocutorilor, a celor care transmit mesajul;

- lipsesc părți esențiale din comunicarea nonverbală şi paraverbală, iar uneori, chiar dacă aceste elemente sunt utilizate eficient, pot suferi modificări în timpul transmiterii mesajului;

dacă în comunicarea tradițională ponderea impactului nonverbal este de 60$90 \%$ și cel verbal de $10-40 \%$, în comunicarea la distanță o pondere importantă din nonverbal va trebui compensat cu elemente verbale, astfel devin esențiale:

$>$ controlul tonului vocii și al volumului;

$>$ selectarea mai atentă a cuvintelor folosite (cuvinte cât mai concrete);

$>$ fluența și ritmul utilizate în conversație;

$>$ delimitarea verbală a subiectelor discutate.

Aceste ultime aspecte pot face obiectul unui studiu ulterior cu privire la îmbunătățirea procedurilor interne privind asigurarea eticii și integrității dar și la identificarea de nevoi ale persoanelor implicate în procesul de soluționare a problemelor de etică (membrii ai comisiilor de etică) și de resurse de acoperire a acestora.

\section{Referințe}

Androniceanu, A., (1990), Managementul schimbării. Valorificarea potenţialului creativ al resurselor umane, București, Editura ALL.

Androniceanu, A., (1998), Managementul schimbărilor, București, Editura ALL.

Băloiu, L.M., (1995), Managementul inovaţiei, Bucureşti, Editura Eficient.

Boehm, P.J., Madeline Justice, Sandy Weeks (2009), Promoting academic integrity in higher education, https://www.schoolcraft.edu/pdfs/cce/15.1.45-61.pdf 2021.

Duca, Gh., (2007), Contribuţii la societatea bazată pe cunoaştere, Chişinău, Editura Ştiința.

Mihailescu, N., (2019), Managementul eticii în instituția școlară, https://ust.md/wp-content/ uploads/2019/12/autoreferat-mihailescu.pdf

Rothman, P., (2017), Ethics in Higher education: A study of the perceived ethical climate of Administrators and Faculty at a higher Education Institution, Educational Doctoral. http://fisherpub.sjfc.edu/education etd/289- Paper 287

Socaciu E., Vică, C., Mihailov, E., Gibea, T., Mureșan, V., Constantinescu, M., (2018), Etică și integritate academică, Bucureşti, Editura Universitatea București.

Ștefan, E.E., (2018), Etică și integritate academică, Editura Pro Universitaria. 